\title{
Low concentrations of glycine inhibit photorespiration and enhance the net rate of photosynthesis in Caragana korshinskii
}

\author{
T. KANG ${ }^{*}$, H.D. WU*, B.Y. LU, X.J. LUO, C.M. GONG, and J. BAI \\ College of Life Sciences, Northwest A\&F University, Yangling 712100, Shaanxi, China
}

\begin{abstract}
The inhibition of photorespiration can be used to improve plant carbon fixation. In order to compare the effects of three photorespiration inhibitors [glycine, $\mathrm{NaHSO}_{3}$, and isonicotinyl hydrazide (INH)], photosynthetic parameters of leaves sprayed respectively with these chemicals were examined and their inhibiting efficiency was evaluated in Caragana korshinskii. Our results showed that $5 \mathrm{mM}$ glycine could reduce the photorespiratory rate $\left(P_{\mathrm{R}}\right)$ effectively, while the net photosynthetic rate $\left(P_{\mathrm{N}}\right)$, stomatal conductance $\left(g_{\mathrm{s}}\right)$, and intercellular $\mathrm{CO}_{2}$ concentration $\left(C_{\mathrm{i}}\right)$ significantly increased. The ratio of electron flow for ribulose-1,5-bisphosphate (RuBP) carboxylation to RuBP oxygenation was elevated markedly. $\mathrm{NaHSO}_{3}$ and INH could also suppress the $P_{\mathrm{R}}$ in some cases, whereas $P_{\mathrm{N}}$ was not improved. The glyoxylate content increased considerably after application of low concentrations of glycine. These results suggested that low concentrations of glycine could suppress photorespiration by feed-back inhibition of glyoxylate and enhance photosynthesis by regulating $g_{\mathrm{s}}, C_{\mathrm{i}}$, and the distribution of electron flow in C. korshinskii.
\end{abstract}

Additional key words: chlorophyll fluorescence; gas exchange; nonstomatal factor; positive correlation; stomatal factor.

\section{Introduction}

In the photosynthetic process, Rubisco (a bifunctional enzyme) catalyzes RuBP carboxylation and oxygenation (Sidhu et al. 2014). The $\left[\mathrm{CO}_{2}\right] /\left[\mathrm{O}_{2}\right]$ ratio and temperature jointly determine whether RuBP is carboxylated or oxygenated (Khan 2007). Under most conditions, the probability of Rubisco binding to $\mathrm{O}_{2}$ is approximately half that of its probability of binding $\mathrm{CO}_{2}$, meaning that every third molecule of RuBP is oxygenated (Bauwe et al. 2012). Therefore, photorespiration consumes much of photosynthetic products (Bauwe et al. 2010). Meanwhile, photorespiration wastes ATP (Voss et al. 2013), reduces NADH/NADPH, and releases organic nitrogen (Hirel et al. 2007). These observations suggest that photorespiration is a wasteful metabolism in plants (Peterhansel and Maurino 2011). Consequently, it is possible that reducing photorespiration might be a primary mean for increasing photosynthesis and yields in plants (Peterhansel et al. 2013).
Although several studies have provided evidence for increasing photosynthesis and yield by spraying plants with the appropriate photorespiration inhibitors, effects of these inhibitors remain controversial. Bisulphite $\left(\mathrm{HSO}_{3}{ }^{-}\right)$ has been found to react with glyoxylate to generate $\alpha$-hydroxylsulphonates, which can inhibit the activity of glycolate oxidase (GO), a key photorespiratory enzyme, in order to block the oxygenation of glycolate (Zelitch 1957). It has been reported that $P_{\mathrm{N}}$ could be enhanced by treatment with low concentrations of bisulphite which suppresses $P_{\mathrm{R}}$ in wheat (Wang et al. 2000a), rice (Wang et al. 2000b), tea trees (Yang et al. 2008), strawberry plants (Guo et al. 2006), and cyanobacterium (Wang et al. 2003). However, the inhibiting effect of $\mathrm{NaHSO}_{3}$ on photorespiratory process was not obvious in soybeans (Takenmoto and Noble 1982). INH could inhibit the activity of glycine decarboxylase (GDC) and subsequently

Received 25 March 2016, accepted 18 November 2016, published as online-first 8 February 2017.

${ }^{+}$Corresponding author; phone: +8613325475383 , e-mail: baijuan@nwsuaf.edu.cn

Abbreviations: $\mathrm{CE}$ - carboxylation efficiency; $\mathrm{Chl}$ - chlorophyll; $\mathrm{C}_{\mathrm{i}}-$ intercellular $\mathrm{CO}_{2}$ concentration; $\mathrm{F}_{0}$ - minimal fluorescence yield of the dark-adapted state; $\mathrm{F}_{\mathrm{m}}$ - maximal fluorescence yield of the dark-adapted state; $\mathrm{F}_{\mathrm{m}}$ - maximal fluorescence yield of the lightadapted state; $\mathrm{F}_{\mathrm{s}}$ - steady-state fluorescence yield; $\Delta \mathrm{F} / \mathrm{F}_{\mathrm{m}}{ }^{\prime}$ - effective quantum yield of PSII photochemistry; FM - fresh mass; GDC - glycine decarboxylase; GGAT - glutamate:glyoxylate aminotransferase; GO - glycolate oxidase; $g_{\mathrm{s}}$ - stomatal conductance; INH - isonicotinyl hydrazide; $\mathrm{J}_{\mathrm{c}}$ - electron flow to RuBP carboxylation; $\mathrm{J}_{\mathrm{o}}$ - electron flow to RuBP oxygenation; $\mathrm{J}_{\mathrm{T}}-$ total electron transport rate; $P_{\mathrm{N}}-$ net photosynthetic rate; $P_{\mathrm{R}}$ - photorespiratory rate; $R_{\mathrm{D}}$ - respiration rate; RuBP - ribulose-1,5-bisphosphate; SGAT - serine:glyoxylate aminotransferase; SHMT - serine hydroxymethyl transferase.

Acknowledgements: This study was funded by the National Natural Science of China (31100455 and 31070538). We are grateful to Dr. Guillaume Queval and Dr. Pengbo Ning for useful suggestions and discussions about the manuscript.

${ }^{*}$ T. Kang and H.D. Wu have equally contributed to this work, and should be both regarded as the first author. 
block the glycolate oxidation in the photorespiratory pathway (Zelitch 1972). Wild and transgenic rice cultured in MS medium containing INH exhibited no photorespiratory activity (Hoshida et al. 2000). Similar to this, the photorespiration rate in Reaumuria soongorica has been found to be reduced by spraying the plant with INH (Bai et al. 2008). Glycine is an intermediate metabolite of photorespiratory process. During the photorespiratory metabolism, glutamate:glyoxylate aminotransferase (GGAT) and serine:glyoxylate aminotransferase (SGAT) catalyse the synthesis of glycine, which is the substrate of GDC. The glycine content of leaves is generally considered to be a sensitive indicator for alterations in photorespiratory carbon flow (Eisenhut et al. 2007). Glycine accumulation leads to an increase in certain photorespiratory intermediates, such as glyoxylate, which can feed back onto Rubisco (Häusler et al. 1996) and change the stoichiometry between electron transport and carbon

\section{Materials and methods}

Plant growth conditions and treatments: Two-year-old C. korshinskii seedlings were grown in the Northwest A\&F University experimental field in Yangling, Shaanxi. The experiment was conducted in August 2013. Three photorespiration inhibitors: glycine $(5,10$, or $20 \mathrm{mM}$, Amresco, USA), $\mathrm{NaHSO}_{3}$ (5, 10, or 20 mM, Sigma, USA), and INH $(5,10$, or $20 \mathrm{mM}$, Alfa, USA) were respectively sprayed on the leaves of $C$. korshinskii at 06:00 h every day for $3 \mathrm{~d}$ prior to measurements. For every inhibitor, a total volume of $50 \mathrm{ml}$ was sprayed on leaves of each plant. Each treatment was carried on three plants. Control plants were sprayed with water. All plants were well watered, and the moisture-holding capacity was appropriately maintained at $80 \%$. Fresh C. korshinskii leaves of each plant were collected at noon on the day when measurement was carried out, and then stored in liquid nitrogen to determine glyoxylate and $\mathrm{Chl}$ contents.

Gas exchange and $\mathrm{Chl} \boldsymbol{a}$ fluorescence measurements: Adult and healthy leaves were used for gas-exchange measurements using a portable photosynthesis system (LI-6400XT, LI-COR, Lincoln, Nebraska, USA) and Chl $a$ fluorescence using a pulse-modulated fluorescence monitor system (FMS-2, Hansatech, UK). Parameters were monitored in all plants every two hours from 09:00 to $15: 00 \mathrm{~h}$ on the day of the experiment. The measurements were replicated three times with one plant. $P_{\mathrm{N}}, C_{\mathrm{i}}$, and $g_{\mathrm{s}}$ were measured directly by portable photosynthesis system. Environmental conditions in chamber were kept for leaf temperature of $25-30^{\circ} \mathrm{C}$, an ambient $\mathrm{CO}_{2}$ concentration of 400-440 $\mu \mathrm{mol} \mathrm{mol}{ }^{-1}$, and the relative humidity was maintained at $70 \%$.

The same leaves were used to assay the Chl $a$ fluorescence. Leaf samples were dark-adapted for $30 \mathrm{~min}$. A low light $\left[<0.1 \mu \mathrm{mol}\right.$ (photon) $\left.\mathrm{m}^{-2} \mathrm{~s}^{-1}\right]$ was used to determine the minimal fluorescence yield of the dark-adapted state assimilation (Leegood et al. 1995).

Caragana korshinskii Kom. (Fabraceae), a dominant shrub species in arid and semiarid areas, is widespread in the wilderness of western and northern China (Fang et al. 2011, Xu et al. 2012). The plant is very tolerant to drought, cold, salt, and other abiotic stresses (Yang et al. 2014) and plays an important role in holding sand, improving the soil, and serving as supplemental livestock forage in the Loess Plateau (Fang et al. 2008; Yan et al. 2012). However, a high $P_{\mathrm{R}}$ was found in the plants living in this area, which was caused by climatic features, such as intense sunlight, high temperature, and low humidity. In order to test the effects of three photorespiration inhibitors $\left(\mathrm{NaHSO}_{3}, \mathrm{INH}\right.$, and glycine), the gas exchange, chlorophyll (Chl) fluorescence parameters, and glyoxylate content were measured to evaluate the effects on $P_{\mathrm{N}}, P_{\mathrm{R}}$, and electron transport rate in C. korshinskii.

$\left(\mathrm{F}_{0}\right)$. In order to measure the maximal fluorescence yield of the dark-adapted state $\left(\mathrm{F}_{\mathrm{m}}\right)$, a 0.8 -s saturating pulse $\left[5,000 \mu \mathrm{mol}\right.$ (photon) $\left.\mathrm{m}^{-2} \mathrm{~s}^{-1}\right]$ was applied. A continuous illumination with actinic light $\left[1,500 \mu \mathrm{mol}\left(\right.\right.$ photon) $\left.\mathrm{m}^{-2} \mathrm{~s}^{-1}\right]$ was used to assay the steady-state fluorescence yield $\left(\mathrm{F}_{\mathrm{s}}\right)$ and maximal fluorescence yield of the light-adapted state $\left(\mathrm{F}_{\mathrm{m}}{ }^{\prime}\right)$. Every plant was measured three times. Effective quantum yield of PSII photochemistry $\left(\Delta \mathrm{F} / \mathrm{F}_{\mathrm{m}}{ }^{\prime}\right)$ was calculated using the equation: $\Delta \mathrm{F} / \mathrm{F}_{\mathrm{m}}{ }^{\prime}=\left(\mathrm{F}_{\mathrm{m}}{ }^{\prime}-\mathrm{F}_{\mathrm{s}}\right) / \mathrm{F}_{\mathrm{m}}{ }^{\prime}(\mathrm{Xu}$ et al. 2012). Total electron transport rate $\left(\mathrm{J}_{\mathrm{T}}\right)$ was calculated using the equation: $\mathrm{J}_{\mathrm{T}}=\Delta \mathrm{F} / \mathrm{F}_{\mathrm{m}}{ }^{\prime} \times \mathrm{PPFD} \times 0.5 \times 0.84$ (Fang et al. 2011, Yan et al. 2012). The respiration rate $\left(R_{\mathrm{D}}\right)$ was calculated using the equation: $R_{\mathrm{D}}=R_{\mathrm{N}} \times \mathrm{Q}_{10}{ }^{(\mathrm{Td}-\mathrm{Tn}) / 10}$ (with $\mathrm{Q}_{10}=2.2$, Td was the leaf temperature; Tn was leaf temperature at dawn, $R_{\mathrm{N}}$ was respiratory rate) (Bai et al. $2008)$. The electron flow to RuBP carboxylation $\left(\mathrm{J}_{\mathrm{c}}\right)$ was calculated using the equation: $\mathrm{J}_{\mathrm{c}}=1 / 3\left[\mathrm{~J}_{\mathrm{T}}+8 \times\left(P_{\mathrm{N}}+R_{\mathrm{D}}\right)\right]$. The electron flow to RuBP oxygenation $\left(\mathrm{J}_{\mathrm{o}}\right)$ was calculated using the equation: $\mathrm{J}_{\mathrm{o}}=2 / 3\left[\mathrm{~J}_{\mathrm{T}}-4 \times\left(P_{\mathrm{N}}+R_{\mathrm{D}}\right)\right]$. $P_{\mathrm{R}}$ was calculated using the equation: $P_{\mathrm{R}}=1 / 12\left[\mathrm{~J}_{\mathrm{T}}-4 \times\left(P_{\mathrm{N}}+\right.\right.$ $R_{\mathrm{D}}$ )] (Guan et al. 2004a).

Glyoxylate content: Glyoxylate was extracted and measured as described by Fahnenstich et al. (2008). Leaf material $(100 \mathrm{mg})$ was homogenized in $1 \mathrm{ml}$ of $100 \mathrm{mM}$ $\mathrm{HCl}$ and $0.1 \%$ phenylhydrazine. The extracts were incubated $80^{\circ} \mathrm{C}$ for $5 \mathrm{~min}$, then chilled on ice for $10 \mathrm{~min}$ and centrifuged at $10,000 \times g$ for $2 \mathrm{~min}$. The $200 \mu \mathrm{l}$ of the supernatant was mixed with $750 \mu \mathrm{l}$ of $18.5 \% \mathrm{HCl}$ and $50 \mu \mathrm{l}$ of $4 \%(\mathrm{w} / \mathrm{v}) \mathrm{K}_{3} \mathrm{Fe}(\mathrm{CN})_{6}$. The mixture was centrifuged at $10,000 \times g$ for $2 \mathrm{~min}$ and the absorbance of the supernatant was measured by a spectrophotometer at $520 \mathrm{~nm}(V-1100 D, M A P A D A$, China) exactly $8 \mathrm{~min}$ after the addition of $\mathrm{K}_{3} \mathrm{Fe}(\mathrm{CN})_{6}$. As a control, $\mathrm{K}_{3} \mathrm{Fe}(\mathrm{CN})_{6}$ was omitted. Absorbance values were quantified using a standard curve generated from known concentrations of 
glyoxylate. Glyoxylate content was expressed as mmol glyoxylate per gram of fresh mass of the sample.

Chl content assay: Chl content was assayed according to the method of Huang et al. (2015) with a few modifications. Fresh leaves of $0.1 \mathrm{~g}$ were ground with cold $80 \%$ acetone solution. All manipulations were performed in dark environment. The absorbance was measured at $665 \mathrm{~nm}$ and $649 \mathrm{~nm}$ (spectrophotometer, $V-1100 D, M A P A D A$, China). The calculation of $\mathrm{Chl} a$ and $\mathrm{Chl} b$ contents $\left[\mathrm{mg} \mathrm{g}^{-1}(\mathrm{FM})\right]$ was done based on the following equations:

$$
\text { Chl } a=\left[\left(13.95 \mathrm{~A}_{665}-6.88 \mathrm{~A}_{649}\right) \times \mathrm{V}\right] /(1000 \times \mathrm{W})
$$

\section{Results}

The effects of photorespiration inhibitors on $\boldsymbol{P}_{\mathrm{R}}$ and $\boldsymbol{P}_{\mathrm{N}}$ : The $P_{\mathrm{R}}$ of $C$. korshinskii decreased after all the treatments with glycine, $\mathrm{NaHSO}_{3}$, and INH (Fig. $1 A-C$ ). Notably, after the treatment with $5 \mathrm{mM}$ glycine, $P_{\mathrm{R}}$ significantly decreased by 48.0, 25.5, 22.0, and 31.3\% at 09:00, 11:00, 13:00, and 15:00 h, respectively (Fig. 1A). $P_{\mathrm{N}}$ increased from 11.19 to $17.04 \mu \mathrm{mol}\left(\mathrm{CO}_{2}\right) \mathrm{m}^{-2} \mathrm{~s}^{-1}$ at 9:00 h, 10.65 to $13.36 \mu \mathrm{mol}\left(\mathrm{CO}_{2}\right) \mathrm{m}^{-2} \mathrm{~s}^{-1}$ at $11: 00 \mathrm{~h}, 4.98$ to $10.67 \mu \mathrm{mol}$ $\left(\mathrm{CO}_{2}\right) \mathrm{m}^{-2} \mathrm{~s}^{-1}$ at 13:00 $\mathrm{h}$, and from 4.14 to $8.38 \mu \mathrm{mol}\left(\mathrm{CO}_{2}\right)$ $\mathrm{m}^{-2} \mathrm{~s}^{-1}$ at 15:00 $\mathrm{h}$ after the treatment with $5 \mathrm{mM}$ glycine,

$$
\mathrm{Chl} b=\left[\left(24.96 \mathrm{~A}_{649}-7.32 \mathrm{~A}_{665}\right) \times \mathrm{V}\right] /(1000 \times \mathrm{W})
$$

where $A_{\lambda}$ was the absorbance at the specific wavelength, $\mathrm{V}$ was the volume of the extracted liquid, and $\mathrm{W}$ was the fresh mass of the sample.

Statistical analysis: All data were calculated in MS Excel (version 2003). Significance and correlation analysis were performed using SPSS for Windows (version 17.0). Oneway analysis of variance (ANOVA) method (LSD model) was used to detect the significance $(P<0.05)$. Data were presented as the means \pm SD. All figures were drawn using Origin 9.1.

respectively (Fig. $1 D$ ). The $5 \mathrm{mM} \mathrm{NaHSO}$ treatment effectively suppressed $P_{\mathrm{R}}$ at 09:00 and 13:00 h (Fig. 1B), but $P_{\mathrm{N}}$ did not raise (Fig. $1 E$ ). For INH treatments, both $P_{\mathrm{N}}$ and $P_{\mathrm{R}}$ were not influenced significantly except for $20 \mathrm{mM}$ $\mathrm{INH}$ at 9:00 $\mathrm{h}$. In addition, the $P_{\mathrm{N}}$ diurnally decreased in all treatments. A comprehensive evaluation of the effect of different treatments on photosynthesis and photorespiratory process is shown in Fig. 2. It is obvious that all inhibitor treatments could depress $P_{\mathrm{R}}$. Glycine $(5 \mathrm{mM})$ was the most effective in inhibiting photorespiration. Both

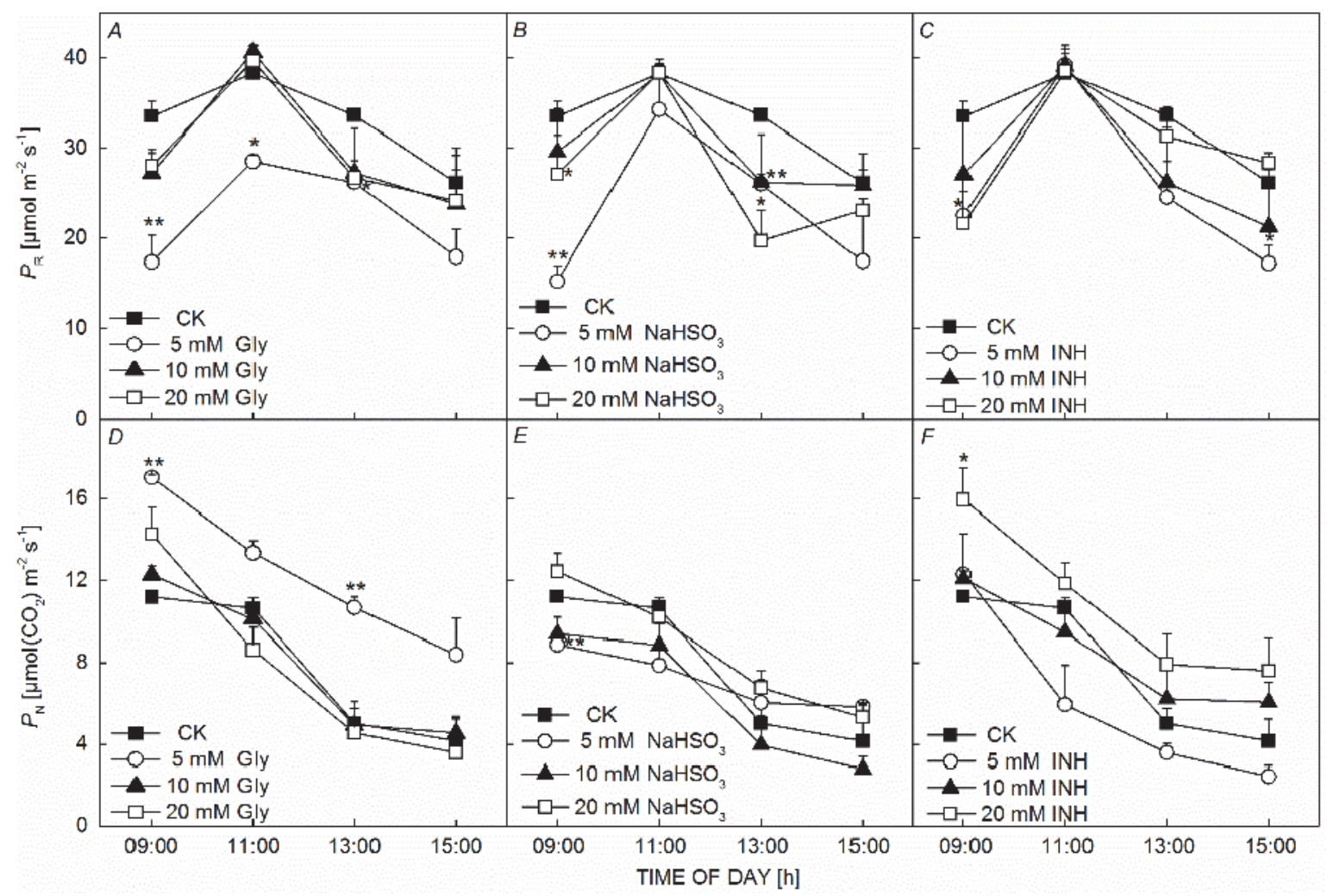

Fig. 1. The effects of various concentrations of glycine $(A), \mathrm{NaHSO}_{3}(B)$, and isonicotinyl hydrazide (INH) $(C)$ on photorespiratory rate $\left(P_{\mathrm{R}}\right)$ and of various concentrations of glycine $(D), \mathrm{NaHSO}_{3}(E)$, and $\mathrm{INH}(F)$ on net photosynthetic rate $\left(P_{\mathrm{N}}\right)$ in Caragana korshinskii at different times during a day. The values represent means $\pm \mathrm{SD}(n=9)$. Significant differences between the treatments and the control are indicated using asterisks $(* P<0.05, * * P<0.01)$. 


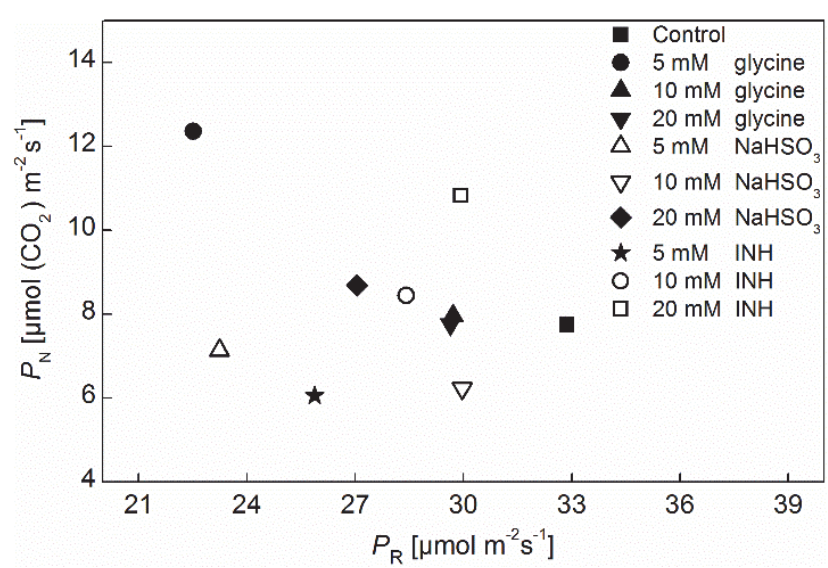

Fig. 2. Comprehensive evaluation of various concentrations of glycine, $\mathrm{NaHSO}_{3}$, and isonicotinyl hydrazide (INH) on photorespiratory rate $\left(P_{\mathrm{R}}\right)$ and net photosynthetic rate $\left(P_{\mathrm{N}}\right)$. The values represent means. The optimal treatments located in upper left show the highest $P_{\mathrm{N}}$ and lowest $P_{\mathrm{R}}$.
$5 \mathrm{mM}$ glycine and $20 \mathrm{mM}$ INH could enhance $P_{\mathrm{N}}$ effectively. Taken together, $5 \mathrm{mM}$ glycine was the optimal treatment for reducing $P_{\mathrm{R}}$ and improving $P_{\mathrm{N}}$ in all treatments (Fig. 2).

The effects of photorespiration inhibitors on $g_{\mathrm{s}}$ and $\boldsymbol{C}_{\mathrm{i}}$ : It was found that $g_{\mathrm{s}}$ progressively decreased during the day time, but this pattern depended on each treatment (Fig. $3 A, B, C) . g_{\mathrm{s}}$ progressively declined from 0.11 at 9:00 h to $0.05 \mathrm{~mol}\left(\mathrm{H}_{2} \mathrm{O}\right) \mathrm{m}^{-2} \mathrm{~s}^{-1}$ at 15:00 h in control, $C_{\mathrm{i}}$ changed from 227.17 to $181.2 \mu \mathrm{mol}\left(\mathrm{CO}_{2}\right) \mathrm{mol}^{-1}$. When $5 \mathrm{mM}$ glycine was applied, $g_{\mathrm{s}}$ fluctuated from $0.18 \mathrm{~mol}$ $\left(\mathrm{H}_{2} \mathrm{O}\right) \mathrm{m}^{-2} \mathrm{~s}^{-1}$ at 9:00 $\mathrm{h}$ to $0.09 \mathrm{~mol}\left(\mathrm{H}_{2} \mathrm{O}\right) \mathrm{m}^{-2} \mathrm{~s}^{-1}$ at 15:00 h, while $C_{\mathrm{i}}$ changed from $284.03 \mu \mathrm{mol}\left(\mathrm{CO}_{2}\right) \mathrm{mol}^{-1}$ to $225.84 \mu \mathrm{mol}\left(\mathrm{CO}_{2}\right) \mathrm{mol}^{-1}$ (Fig. $\left.3 A, D\right)$. The $10 \mathrm{mM}$ and $20 \mathrm{mM}$ glycine treatments did not markedly affect $g_{\mathrm{s}}$ and $C_{\mathrm{i}}$ (Fig. $3 A, D$ ). All of $\mathrm{NaHSO}_{3}$ treatments did not alter $g_{\mathrm{s}}$ and $C_{\mathrm{i}}$ except the increase of $C_{\mathrm{i}}$ with $5 \mathrm{mM} \mathrm{NaHSO}$ at 15:00 h (Fig. $3 B, E) . g_{\mathrm{s}}$ declined obviously with $5 \mathrm{mM} \mathrm{INH}$

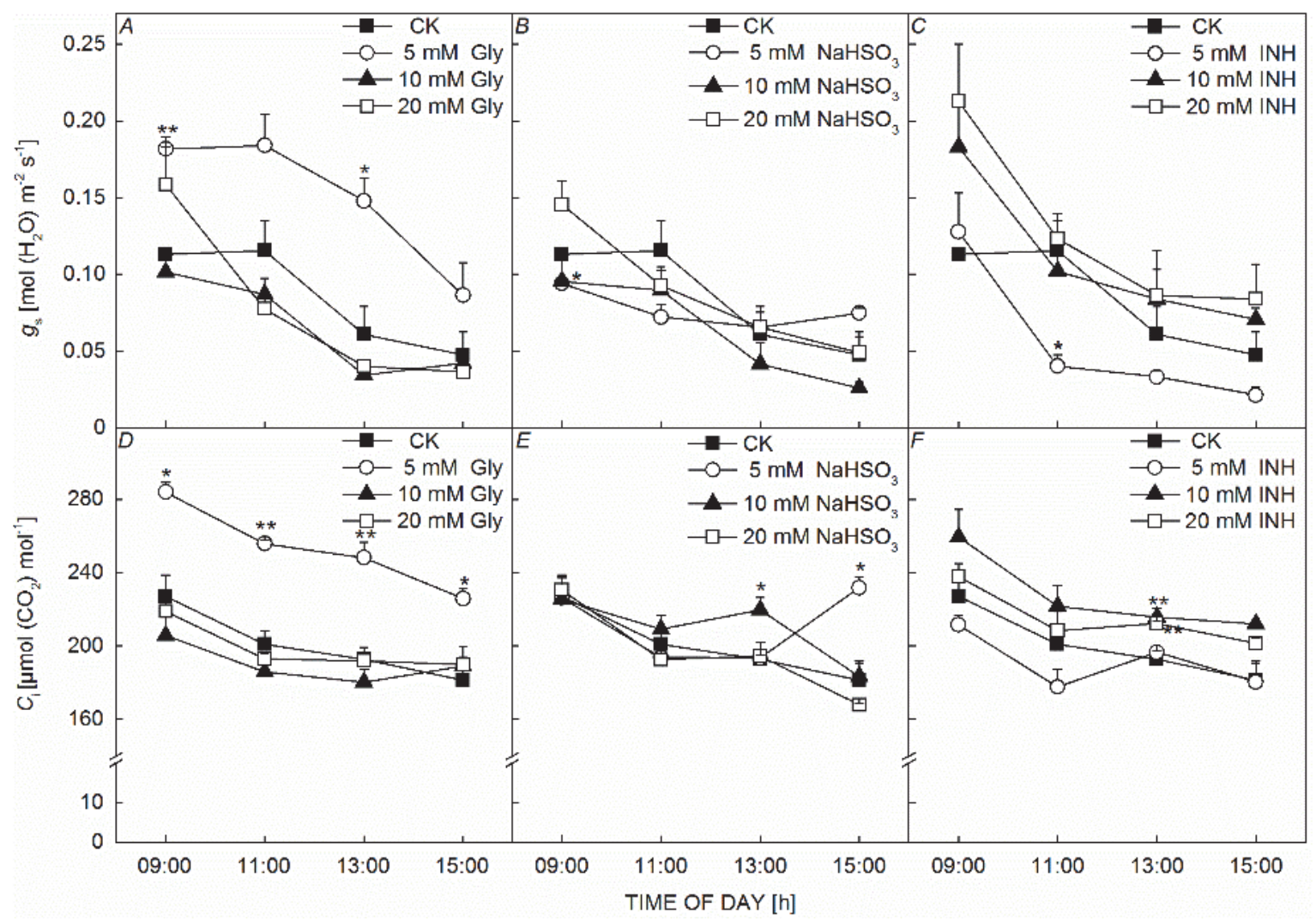

Fig. 3. The effects of various concentrations of glycine $(A), \mathrm{NaHSO}_{3}(B)$, and isonicotinyl hydrazide (INH) $(C)$ on stomatal conductance $\left(g_{\mathrm{s}}\right)$ and of various concentrations of glycine $(D), \mathrm{NaHSO}_{3}(E)$, and $\mathrm{INH}(F)$ on intercellular $\mathrm{CO}_{2}$ concentration $\left(C_{\mathrm{i}}\right)$ in Caragana korshinskii at different times during the day. The values shown represent means $\pm \operatorname{SD}(n=9)$. Significant differences between the treatments and the control are indicated by asterisks $(* P<0.05, * * P<0.01)$.

at 11:00 h (Fig. $3 C$ ). $C_{\text {i }}$ rose significantly with $10 \mathrm{mM}$ and $20 \mathrm{mM}$ INH at 13:00 h (Fig. 3F). Taken as a whole, $g_{\mathrm{s}}$ and $C_{\mathrm{i}}$ showed the similar inhibition effects, especially, with $5 \mathrm{mM}$ glycine. A positive correlation was found between
$C_{\mathrm{i}}$ and $P_{\mathrm{N}}$ (Fig. 4). These results suggested that $5 \mathrm{mM}$ glycine could effectively enhance $g_{\mathrm{s}}$ and $C_{\mathrm{i}}$, and then lead to the elevation of $P_{\mathrm{N}}$. 
The effects of photorespiration inhibitors on $\mathbf{J}_{\mathrm{c}} / \mathbf{J}_{\mathrm{T}}$ and $\mathbf{J}_{\mathrm{c}} / \mathbf{J}_{\mathbf{o}}$ : The value $\mathrm{J}_{\mathrm{c}} / \mathbf{J}_{\mathrm{T}}$ is an indication of the conversion of electron energy to active chemical energy. It was obvious that $5 \mathrm{mM}$ glycine could elevate the value every time, and the most significant effect was found at 9:00 and 13:00 h (Fig. $5 A$ ), while $10 \mathrm{mM}$ and $20 \mathrm{mM}$ glycine markedly increased $\mathrm{J}_{\mathrm{c}} \mathrm{J}_{\mathrm{T}}$ at 9:00 h (Fig. $5 A$ ). The value of $\mathrm{J}_{\mathrm{c}} / \mathrm{J}_{\mathrm{T}}$ rose significantly with $5 \mathrm{mM} \mathrm{NaHSO}$ at $09: 00 \mathrm{~h}$ and $20 \mathrm{mM}$ $\mathrm{NaHSO}_{3}$ at 13:00 h (Fig. 5B), as well as with $20 \mathrm{mM} \mathrm{INH}$ at 9:00 h (Fig. 5C). Correspondingly, $5 \mathrm{mM}$ glycine could increase the value of $\mathrm{J}_{\mathrm{c}} / \mathrm{J}_{\mathrm{o}}$ significantly most of the time (Fig. $5 D$ ). The value of $\mathrm{J}_{\mathrm{c}} / \mathrm{J}_{\mathrm{o}}$ was elevated after the $5 \mathrm{mM}$ $\mathrm{NaHSO}_{3}$ treatment at 09:00 h (Fig. 5E) and $20 \mathrm{mM}$ $\mathrm{NaHSO}_{3}$ treatment at 13:00 h (Fig. 5E). Our results suggested that the chemicals inhibited photorespiration, which led to a higher electron flow through the Calvin cycle; this influenced $P_{\mathrm{N}}$ and $P_{\mathrm{R}}$, especially after $5 \mathrm{mM}$ glycine treatment. This observation was consistent with the changes observed for $P_{\mathrm{R}}$ and $P_{\mathrm{N}}$.

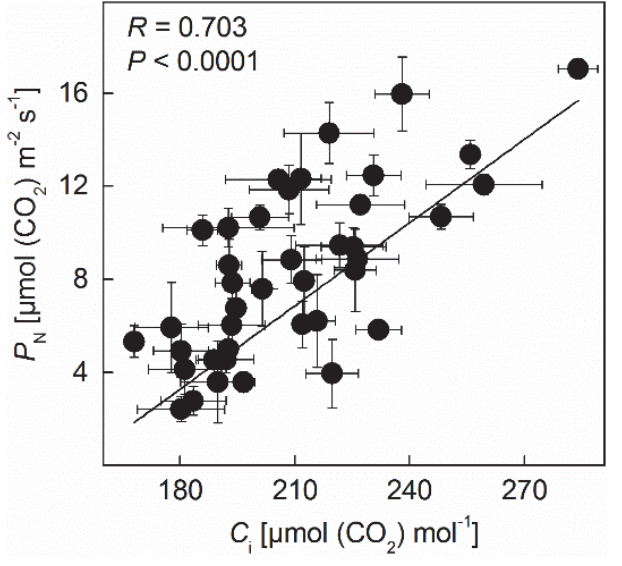

Fig. 4. The correlation analysis between intercellular $\mathrm{CO}_{2}$ concentration $\left(C_{\mathrm{i}}\right)$ and net photosynthetic rate $\left(P_{\mathrm{N}}\right)$. All averages in different treatments at different times were shown. The values represent means $\pm \mathrm{SD}$.

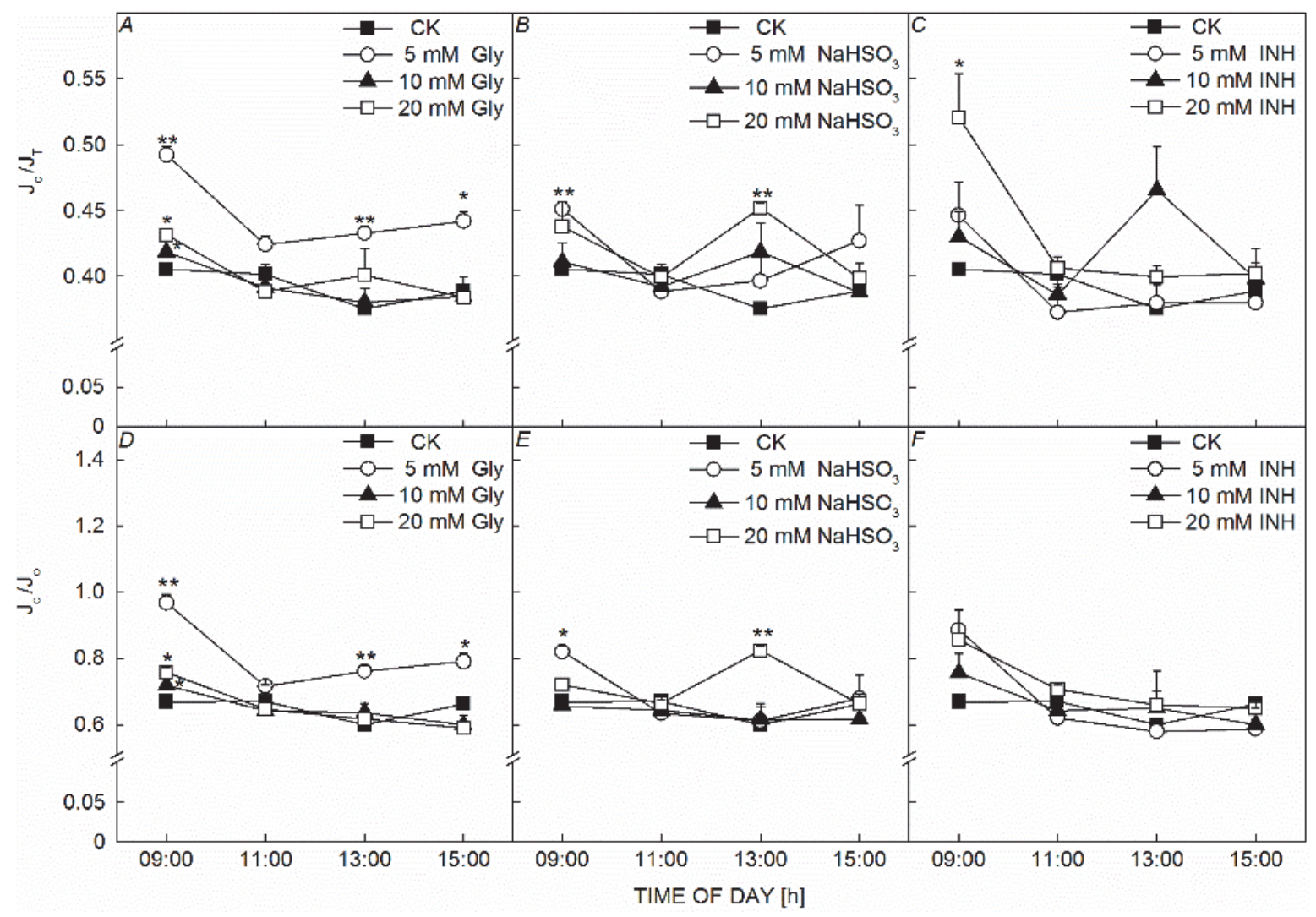

Fig. 5. The effects of various concentrations of glycine $(A), \mathrm{NaHSO}_{3}(B)$, and isonicotinyl hydrazide (INH) $(C)$ on the ratio of electron flow to RuBP carboxylation to total electron transport rate $\left(\mathrm{J}_{\mathrm{c}} / \mathrm{J}_{\mathrm{T}}\right)$ and of various concentrations of glycine $(D), \mathrm{NaHSO}_{3}(E)$, and INH $(F)$ on the ratio of electron flow to RuBP carboxylation to electron flow to RuBP oxygenation $\left(\mathrm{J}_{\mathrm{c}} / \mathrm{J}_{\mathrm{o}}\right)$ in Caragana korshinskii at different times. The values represent means $\pm \mathrm{SD}(n=9)$. Significant differences between the treatments and the control are indicated using asterisks $(* P<0.05, * * P<0.01)$. 


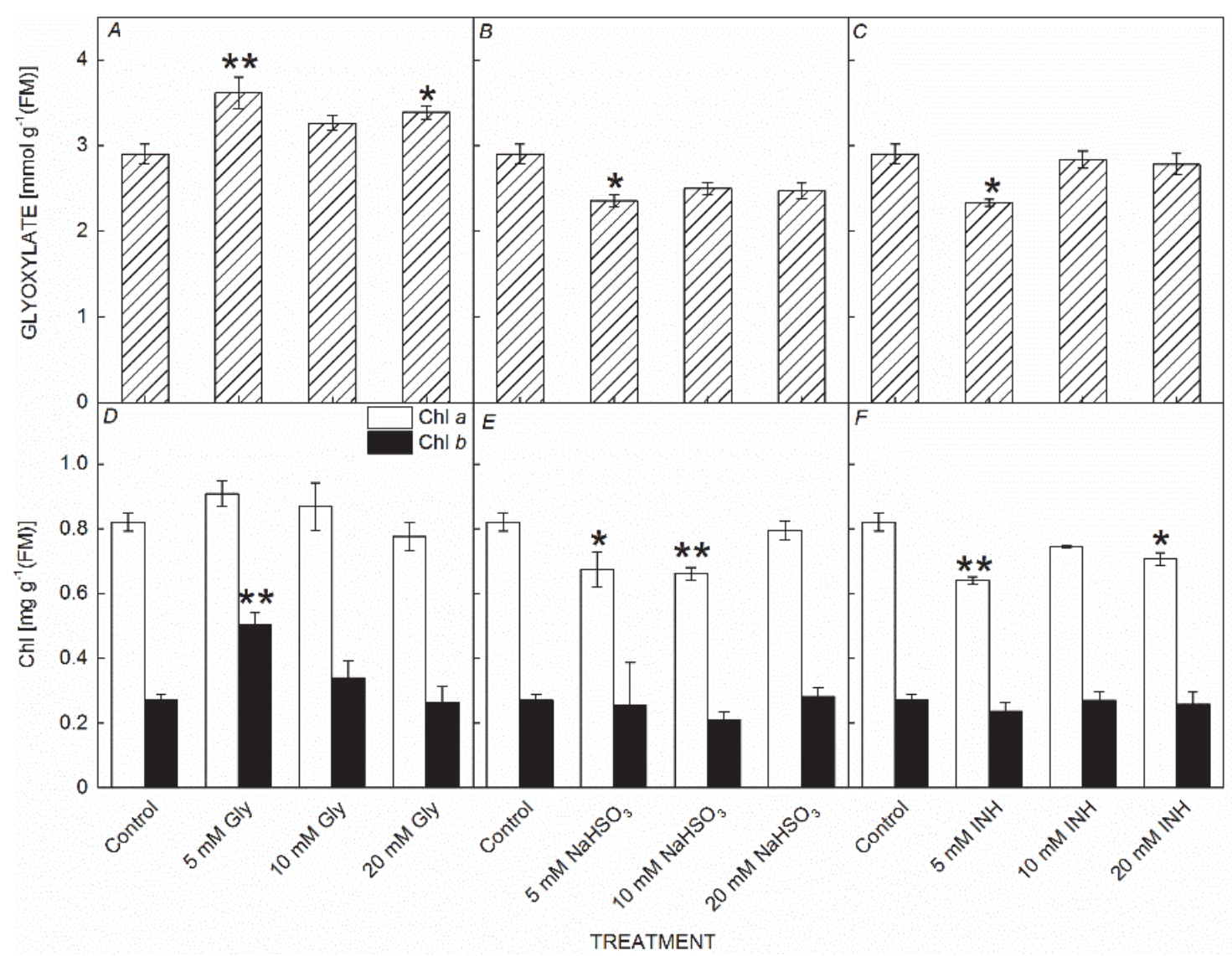

Fig. 6. The effects of various concentration of glycine $(A), \mathrm{NaHSO}_{3}(B)$, and isonicotinyl hydrazide (INH) $(C)$ on glyoxylate contents and of various concentrations of glycine $(D), \mathrm{NaHSO}_{3}(E)$, and INH $(F)$ on chlorophyll (Chl) $a$ and Chl $b$ contents in Caragana korshinskii. The values represent means $\pm \mathrm{SD}(n=9)$. Significant differences between the treatments and the control are indicated by different labels $(* P<0.05, * * P<0.01)$.

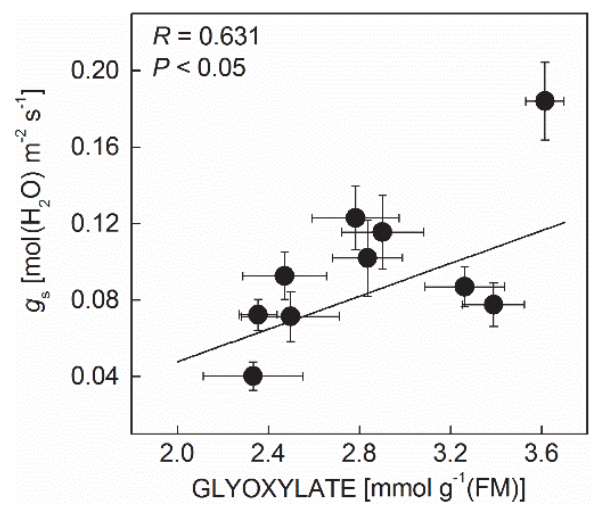

Fig. 7. The correlation analysis between glyoxylate content and stomatal conductance $\left(g_{\mathrm{s}}\right)$ in all treatments. The values shown represent means $\pm \mathrm{SD}$.

The effect of inhibitors of photorespiration on glyoxylate content: Glyoxylate is the major inter-metabolite in the photorespiratory process. The treatment with $5 \mathrm{mM}$ glycine caused a significant increase in the glyoxylate content [from 2.9 to $3.61 \mathrm{mmol} \mathrm{g}^{-1}(\mathrm{FM})$ relative to the control] (Fig. 6A). No significant difference was found after the moderate and high glycine-concentration treatments (Fig. 6A). By contrast, $\mathrm{NaHSO}_{3}$ and INH treatments induced a decline of the glyoxylate content relative to the control plants (Fig. 6B,C). The lowest glyoxylate value was found at $5 \mathrm{mM}$ INH. Compared with the control plants, the glyoxylate content decreased by 18.9 and $19.6 \%$ after the treatments with low concentrations of $\mathrm{NaHSO}_{3}$ and $\mathrm{INH}$, respectively. In addition, a positive correlation was found between the glyoxylate content and $g_{\mathrm{s}}$ (Fig. 7).

The effects of photorespiration inhibitors on Chl content: The treatment with $5 \mathrm{mM}$ glycine induced the increase of the $\mathrm{Chl} b$ content, while no difference was found in the Chl $a$ content (Fig. 6D). However, $\mathrm{NaHSO}_{3}$ and INH treatments resulted in a severe decrease of the Chl a content, especially, with $5 \mathrm{mM} \mathrm{NaHSO}, 10 \mathrm{mM}$ $\mathrm{NaHSO}_{3}, 5 \mathrm{mM} \mathrm{INH}$, and $20 \mathrm{mM}$ INH. Such treatments, however, did not affect the content of Chl $b$ (Fig. 6E,F). 


\section{Discussion}

Reducing photorespiration by utilization of inhibitors might be an effective mean for enhancing photosynthesis in order to promote plant yields. Glycine, $\mathrm{NaHSO}_{3}$, and INH are well-known photorespiration inhibitors. Glycine is an intermediate of the photorespiratory pathway, which could restrain photorespiration by feedback inhibition. In this study, photorespiration was inhibited by all glycine treatments. Especially, $5 \mathrm{mM}$ glycine significantly decreased $P_{\mathrm{R}}$ and increased $P_{\mathrm{N}}$. $\mathrm{HSO}_{3}{ }^{-}$could block photorespiration process by forming $\alpha$-hydroxylsulphonates with glyoxylate to inhibit GO activity (Zelitch 1957). Numerous researches indicated that the application of $\mathrm{NaHSO}_{3}$ to plants was shown to increase $P_{\mathrm{N}}$ in many species (Wang et al. 2003, Guo et al. 2006, Yang et al. 2008, Chen et al. 2014, Liu et al. 2015). In this experiment, all $\mathrm{NaHSO}_{3}$ treatments depressed $P_{\mathrm{R}}$. The greatest effect was found at 09:00 and 13:00 h with $5 \mathrm{mM} \mathrm{NaHSO}$ (Fig. 1B). However, photosynthesis was not markedly enhanced (Fig. 1E). INH can block the glycolate oxygenation (Zelitch 1972) and the activity of GDC in the $\mathrm{C}_{2}$ pathway (Naik 2006). It was reported that INH effectively inhibited photorespiration in Reaumuria soongorica (Bai et al. 2008), Vitis vinifera (Guan et al. 2004b), and rice (Hoshida et al. 2000). In the present study, $5 \mathrm{mM} \mathrm{INH}$ was observed to inhibit photorespiration in C. korshinskii at 09:00 and 15:00 h, whereas photosynthesis was not improved. Taken the effect on photorespiration and photosynthesis together, the low concentration of glycine was the optimal inhibitor in C. korshinskii.

Exogenous glycine might lead to an increase of glyoxylate by feedback inhibition. Glyoxylate is the precursor of oxalate biosynthesis, which can change the concentration of calcium ions in the plant by binding calcium and thus regulate the stomatal aperture (SánchezMartín et al. 2015). Therefore, low concentrations of glycine might increase the content of glyoxylate and decrease the concentration of intracellular calcium ions, thereby promote stomata opening in C. korshinskii. Correlation analysis of glyoxylate content and $g_{\mathrm{s}}$ also supported the hypothesis, resulting in more $\mathrm{CO}_{2}$ transported into intercellular space via stomata.

Stomatal conductance regulates the diffusion of $\mathrm{CO}_{2}$ and the transport of $\mathrm{H}_{2} \mathrm{O}$ in plants, and thus influences

\section{References}

Bai J., Xu D.H., Kang H.M. et al.: Photoprotective function of photorespiration in Reaumuria soongorica during different levels of drought stress in natural light irradiance. Photosynthetica 46: 232-237, 2008.

Bauwe H., Hagemann M., Fernie A.R.: Photorespiration: players, partners and origin. - Trends Plant Sci. 15: 330-336, 2010.

Bauwe H., Hagemann M., Kern R. et al.: Photorespiration has a dual origin and manifold links to central metabolism. - Curr. Opin. Plant Biol. 15: 269-275, 2012. photosynthesis. Previous research has suggested that $C_{\mathrm{i}}$ can be used to evaluate stomatal and nonstomatal factors affecting the values of $P_{\mathrm{N}}$ (Farquhar and Sharkey 1982). A decrease in $P_{\mathrm{N}}$, which correlates to a decrease in $C_{\mathrm{i}}$, is a consequence of stomatal factors, whereas a decrease in $P_{\mathrm{N}}$, which correlates with an increase in $C_{\mathrm{i}}$, may result from nonstomatal factors. Nonstomatal factors usually occurred when plants were subjected to stressful conditions. In the present study, both $C_{\mathrm{i}}$ and $g_{\mathrm{s}}$ were elevated significantly when the plants were treated with the low concentration of glycine compared with the control. Meanwhile, $P_{\mathrm{N}}$ and $C_{\mathrm{i}}$ presented a similar trend. Positive correlation between $C_{\mathrm{i}}$ and $P_{\mathrm{N}}$ also proved the increase of $P_{\mathrm{N}}$ resulted from the elevation of $C_{\mathrm{i}}$. These results suggested that the increase in $P_{\mathrm{N}}$ resulted from stomatal factors under the condition of $5 \mathrm{mM}$ glycine. In addition, $\mathrm{CO}_{2}$ from glycine decarboxylation accounted for $75 \%$ of intercellular $\mathrm{CO}_{2}$ (Kozaki and Takeba 1996), which could also explain the elevation of $C_{\mathrm{i}}$ with $5 \mathrm{mM}$ glycine.

The increase of $C_{\mathrm{i}}$ enhances the local $\mathrm{CO}_{2}$ concentration and the partial pressure of $\mathrm{CO}_{2}$ near Rubisco. Ultimately, CE increased and the oxygenation of RuBP was restricted (Rivero et al. 2009). $\mathrm{J}_{\mathrm{c}} / \mathrm{J}_{\mathrm{T}}$ indicates the relative importance of $J_{c}$. $J_{c} / J_{o}$ is a good index of the relative rates of carboxylation $v s$. oxygenation (Silva et al. 2015). In the present study, of all the inhibitor treatments, the $5 \mathrm{mM}$ glycine treatment exerted the strongest effect on $\mathrm{J}_{\mathrm{c}} / \mathrm{J}_{\mathrm{T}}$ and $\mathrm{J}_{\mathrm{c}} / \mathrm{J}_{\mathrm{o}}$, which implied that more electrons flowed into RuBP carboxylation and that oxygenation was inhibited. The result correlated with the observed changes in $P_{\mathrm{N}}$ and $P_{\mathrm{R}}$.

In summary, the effects of different chemicals on photorespiration and photosynthetic process were evaluated in this experiment. The results suggested that INH and $\mathrm{NaHSO}_{3}$ could reduce $P_{\mathrm{R}}$ to some extent, but the effect on $P_{\mathrm{N}}$ was not obvious. Taken together, $5 \mathrm{mM}$ glycine was the optimal inhibitor based on its effect on $P_{\mathrm{R}}$ and $P_{\mathrm{N}}$. It might be because the low concentration of glycine promoted the accumulation of glyoxylate, which inhibited photorespiration, but also enhanced photosynthesis owing to regulation of $g_{\mathrm{s}}, C_{\mathrm{i}}$, and the distribution of electron flow for RuBP carboxylation and RuBP oxygenation in C. korshinskii.

Chen Y., Jin J.H., Jiang Q.S. et al.: Sodium bisulfite enhances photosynthesis in rice by inducing Rubisco activase gene expression. - Photosynthetica 52: 475-478, 2014.

Eisenhut M., Bauwe H., Hagemann M. et al.: Glycine accumulation is toxic for the cyanobacterium Synechocystis sp. strain PCC 6803, but can be compensated by supplementation with magnesium ions. - FEMS Microbiol. Lett. 277: 232-237, 2007.

Fahnenstich H., Scarpeci T.E., Valle E.M. et al.: Generation of hydrogen peroxide in chloroplasts of Arabidopsis over- 
expressing glycolate oxidase as an inducible system to study oxidative stress. - Plant Physiol. 148: 719-729, 2008.

Fang X.W., Li J.H., Xiong Y.C. et al.: Responses of Caragana korshinskii Kom. to shoot removal: mechanisms underlying regrowth. - Ecol. Res. 23: 863-871, 2008.

Fang X.W., Turner N.C., Li F.M. et al.: Caragana korshinskii seedlings maintain positive photosynthesis during short-term, severe drought stress. - Photosynthetica 49: 603-609, 2011.

Farquhar G., Sharkey T.: Stomatal conductance and photosynthesis. - Annu. Rev. Plant Physio. 33: 317-345, 1982.

Guan X.Q., Zhao S.J., Li D.Q. et al.: Photoprotective functions of photorespiration in several grapevine cultivars under drought stress. - Photosynthetica 42: 31-36, 2004a.

Guan X.Q., Zhao S.J., Li D.Q. et al.: [The effect of inhibited photorespiration on photoinhibition in "cabernet sauvignon" (Vitis vinefera L.cv.) under drought stress.] - Acta Hortic. Sin. 31: 433-436, 2004b. [In Chinese]

Guo Y.P., Peng Y., Lin M.L. et al.: Different pathways are involved in the enhancement of photosynthetic rate by sodium bisulfite and benzyladenine, a case study with strawberry (Fragaria $\times$ Ananassa Duch) plants. - Plant Growth Regul. 48: 65-72, 2006.

Häusler R.E., Bailey K.J., Lea P.J. et al.: Control of photosynthesis in barley mutants with reduced activities of glutamine synthetase and glutamate synthase III. Aspects of glyoxylate metabolism and effects of glyoxylate on the activation of ribulose-1,5-bisphosphate carboxylase-oxygenase. - Planta 200: 388-396, 1996.

Hirel B., Le Gouis J., Ney B. et al.: The challenge of improving nitrogen use efficiency in crop plants: towards a more central role for genetic variability and quantitative genetics within integrated approaches. - J. Exp. Bot. 58: 2369-2387, 2007.

Hoshida H., Tanaka Y., Hibino T. et al.: Enhanced tolerance to salt stress in transgenic rice that overexpresses chloroplast glutamine synthetase. - Plant Mol. Biol. 43: 103-111, 2000.

Huang C.J., Wei G., Jie Y.C.: Responses of gas exchange, chlorophyll synthesis and ROS-scavenging systems to salinity stress in two ramie (Boehmeria nivea L.) cultivars. Photosynthetica 53: 455-463, 2015.

Khan M.S.: Engineering photorespiration in chlroplasts: a novel strategy for increasing biomass production. - Trends Biotechnol. 25: 437-440, 2007.

Kozaki A., Takeba G.: Photorespiration protects C3 plants from photooxidation. - Nature 384: 557-560, 1996.

Leegood R.C., Lea P.J., Adcock M.D. et al.: The regulation and control of photorespiration. - J. Exp. Bot. 46: 1397-1414, 1995.

Liu L.Y., Wang Z.X., Zhao X.H. et al.: Effects of different photorespiration inhibitors on photosynthetic characteristics and berry quality of Vitis amurensis Rupr. - Can. J. Plant Sci. 95: 1-10, 2015.

Naik R.M.: Dependence of in vivo nitrate reduction on photorespiration and mitochondrial respiration in leaves of Nicotiana sylvestris. - J. Plant. Biochem. Biot. 15: 59-61, 2006.

Peterhansel C., Krause K., Braun H.P. et al.: Engineering photorespiration: current state and future possibilities. - Plant Biol. 15: 754-758, 2013.

Peterhansel C., Maurino V.G.: Photorespiration redesigned. -
Plant Physiol. 155: 49-55, 2011.

Rivero R.M., Shulaev V., Blumwald E.: Cytokinin-dependent photorespiration and the protection of photosynthesis during water deficit. - Plant Physiol. 150: 1530-1540, 2009.

Sánchez-Martín J., Heald J., Kingston-Smith A. et al.: A metabolomic study in oats (Avena sativa) highlights a drought tolerance mechanism based upon salicylate signalling pathways and the modulation of carbon, antioxidant and photooxidative metabolism. - Plant Cell Environ. 38: 1435-1452, 2015.

Sidhu G.K., Mehrotra R., Mehrotra S.: Carbon concentration mechanisms: in rescue of Rubisco inefficiency. - Acta Physiol. Plant. 36: 3101-3114, 2014.

Silva E.N., Silveira J.A.G., Ribeiro R.V. et al.: Photoprotective function of energy dissipation by thermal processes and photorespiratory mechanisms in Jatropha curcas plants during different intensities of drought and after recovery. - Environ. Exp. Bot. 110: 36-45, 2015.

Takenmoto B.K., Noble R.D.: The effects of short-time $\mathrm{SO}_{2}$ fumigation on photosynthesis and respiration in soybean Glycine max. - Environ. Pollut. A 28: 67-74, 1982.

Voss I., Sunil B., Scheibe R. et al.: Emerging concept for the role of photorespiration as an important part of abiotic stress response. - Plant Biol. 15: 713-722, 2013.

Wang H.W., Mi H.L., Ye J.Y. et al.: Low concentrations of $\mathrm{NaHSO}_{3}$ increase cyclic photophosphorylation and photosynthesis in cyanobacterium Synechocystis PCC6803. Photosynth. Res. 75: 151-159, 2003.

Wang H.W., Wei J.M., Shen Y.G.: [Enhancement in wheat leaf photophosphorylation and photosynthesis by spraying low concentration of $\mathrm{NaHSO}_{3}$.] - Chin. Sci. Bull. 45: 1308-1311, 2000a. [In Chinese]

Wang H.W., Wei J.M., Shen Y.G. et al.: Enhancement of photophosphorylation and photosynthesis in rice by low concentrations of $\mathrm{NaHSO}_{3}$ under field conditions. - Acta Bot. Sin. 42: 1295-1299, 2000b.

Xu D.H., Fang X.W., Su P.X. et al.: Ecophysiological responses of Caragana korshinskii Kom. under extreme drought stress: leaf abscission and stem survives. - Photosynthetica 50: 541548, 2012.

Yan H., Hu X.T., Li F.S.: Leaf photosynthesis, chlorophyll fluorescence, ion content and free amino acids in Caragana korshinskii Kom. exposed to $\mathrm{NaCl}$ stress. - Acta Physiol. Plant. 34: 2285-2295, 2012.

Yang Q., Yin J.J., Li G. et al.: Reference gene selection for qRTPCR in Caragana korshinskii Kom. under different stress conditions. - Mol. Biol. Rep. 41: 2325-2334, 2014.

Yang W.J., Chen H.F., Zhu F.Y. et al.: Low concentration of bisulfite enhances photosynthesis in tea tree by promoting carboxylation efficiency in leaves. - Photosynthetica 46: 615617, 2008.

Zelitch I.: $\alpha$-hydroxysulfonates as inhibitors of the enzymatic oxidation of glycolic and lactic acids. - J. Biol. Chem. 224: 251-260, 1957.

Zelitch I.: Comparison of the effectiveness of glycolic acid and glycine as substrates for photorespiration. - Plant Physiol. 50: 109-113, 1972. 